\title{
Functional changes in early child language: the appearance of references to the past and of explanations*
}

\author{
EDY VENEZIANO \\ Université de Genève and Université de Nancy II \\ AN D \\ HERMINA SINCLAIR \\ Université de Genève
}

(Received: 20 fanuary 1993. Revised: 12 Fune 1994)

\begin{abstract}
Spontaneous speech samples from children during the period of transition from one word to multi-word utterances in interaction with their French-speaking mothers were explored in order to study the appearance and development of functional changes in their use of language. Two types of such change were noted in the longitudinal records of four children when they were still essentially one-word speakers: the beginnings of references to the past, and the appearance of explanations and justifications, especially in communicative situations of request and refusal. The co-appearance of these behaviours is discussed in relation to two more general developmental changes: a detachment from the immediately perceptible situation linked to a further elaboration of the signifier-signified relation, and a socio-cognitive development leading to a view of the interlocutor as an alter ego, as a person whose psychological states may be different from the child's own.
\end{abstract}

\section{INTRODUCTION}

An essential characteristic of the use competent speakers make of their language, as many authors have underlined, is that speech can refer to absent

[*] The research reported in this paper was supported in part by the Fonds national suisse de la recherche scientifique (grants no. I I-30927.9 I and no. I I-37304.93 to E. Veneziano and H. Sinclair). Address for correspondence: Edy Veneziano, F.P.S.E., Université de Genève-11, Route de Drize, 1227 Carouge, Switzerland. 
objects and persons, to past or future events as well as to aspects of the actual communicative situation that are not directly perceptible to the interlocutor. This characteristic was called 'displaced speech' by Bloomfield (1935: I4I ; see also Hockett, 1958).

As shown in many observations of early child language, children's utterances are at first essentially linked to the here and now (e.g. Brown \& Bellugi, I 964; Bloom, 1970: 9-10). In a way, the relation between signifier and signified may be considered to follow the direction from signified to signifier: the elements of the situation present elicit their verbalization. Mature speakers, by contrast, use the relation mainly in the other direction, i.e. from signifier to signified: their utterances evoke and interpret entities and events that are not accessible to present observation, and contain grammatical and lexical elements to signal past and future, hypotheses, conclusions, etc. Talking about entities and events removed from the time and place of enunciation or talking about present objects, persons or events underscoring their non perceptible properties is linked to providing information in the broad sense of making the interlocutor 'aware of something of which he was not previously aware' (Lyons, 1977:33).

When do children start to show changes towards the displaced, informative uses of language? To answer this question we will concentrate in this paper on the appearance and early development of displaced uses of language such as references to past events and early story telling, as well as explanatory acts. References to the past are clear instances of displaced speech and have often been studied as such. Explanations and justifications, though not usually studied in this perspective, are also examples of displaced speech in our opinion. When explaining or justifying, speakers clarify for their interlocutor the kinds of links they have constructed in their mind between events, actions and/or utterances, links that are not directly accessible to another person even if $\mathrm{s} / \mathrm{he}$ is present in the situation at the same time as the speaker; moreover, one of the terms of the relation is usually not co-present with the other and is thus temporally displaced relative to the enunciation. Piaget, in his study of older children's explanations, remarks that explanations and justifications imply a distinction between 'the real as it appears immediately to the senses, and something which precedes events and underlies all phenomena' (Piaget, I 923/1959: 232). From a socio-cognitive point of view (Barbieri, Colavita \& Scheuer, 1990), justifications and explanations have yet another important aspect that characterizes them as displaced speech: an explanation does not merely imply that the speaker can make causal links between one event and another; an explanation is viewed as a two-step communicative act in which the first step is to consider that an action or an utterance might constitute a problem for one's interlocutor (that is, might constitute an EXPLANANDUM) and the second consists in providing supplementary information by going back towards the cause, reason or motive 
that precedes it temporally or logically (providing the ExPLANANS). Even if the explanation concerns a present or ongoing event, the speaker mentally needs to effect a displacement relative to that event in order to provide the cause or reason that temporally and/or logically precedes it. According to this approach, explananda can be implicit in the situation (Barbieri et al. 1990: 248) making the explanans and thus explanatory acts possible occurrences even in the very early period of language development.

References to the past by children in the very early period of language acquisition are sometimes found in the literature. Lewis (1936) reports oneword examples of references to the past produced in a dialogic context, e.g. dada uttered as a reply to the question 'Who gave you that box?' Cohen (1952/1969) notes that 'isolated' words may be used to refer to the past and provides examples such as the child saying maman, meaning that mummy had given her the object she held in her hands (1969: 244). Greenfield \& Smith (1976: 172) provide an example of Matthew who at $1 ; 3$. 10 says down when his mother enters the room to report that he came down from somewhere. Conversation and shared experience are often necessary for understanding these early references to the past and for getting the child to elaborate on them. Snow (1978) reports a child aged $1 ; 6$ saying bandaid several times without her understanding what exactly the child meant. The mother, who shared the experience with the child, was able to make the child elaborate her intended meaning by asking the appropriate questions 'Who gave you the bandaid?' to which the child replied nurse and 'Where did she put it ?' to which the child replied arm. Other such examples can be found in Bloom (1970, e.g. p. 57) and in Scollon (1979: 220).

There are few, however, documented studies addressing specifically the question of the beginnings of the capacity to talk about the past since most studies of narratives and references to the past concern children above three years (e.g. Peterson \& McCabe, 1983; Nelson, 1986). A central study is Sachs's analysis ( 1983 ) of the emergence of displaced references in her daughter's utterances. Sachs kept diary notes from the time her daughter was I I months old and made tape recordings of parent-child interactions between the ages of $1 ; 5$ and $3 ; 0$. The first references to the past, produced between $I ; 5$ and 2; 1 , concerned events that had just occurred; all the examples reported were multi-word utterances and frequently contained -ed verbal endings for the past ( $I$ throwed $i t$ ). References to events occurring in a more distant time started to appear at $2 ; 2$ and were expressed in multiword utterances containing verbal morphology and lexical items marking temporal relationships.

Miller \& Sperry ( 1988 ) studied the production of narratives in five children between the ages of $1 ; 7$ and $2 ; 8$. At the beginning of the study all the children were already producing two-word utterances and the first reported example of past reference, produced at $1 ; 7$, consisted of a four-word 
utterance (me big fall down). Other studies (e.g. Eisenberg, 1985 ; Lucariello $\&$ Nelson, 1987; Peterson, 1990) of young children's references to the past also concern children who produced multi-word utterances from the very beginning of the study and looked only for references to events that had taken place at a somewhat distant past (prior to the observational session). These studies suggest that references to earlier past just emerge in the first half of the third year, with children making at first few contributions to mostly adult-initiated past talk.

Studies of children's expression of causality and explanations mostly concern an even later developmental period as they bear on children well beyond the early two-word period. Studies of children between two and three-and-a-half years mainly concerned the appearance and use of various connectives and showed, for example, that the connective because appears between $2 ; 6$ and $3 ; 0$, later than the more general connective and (Limber, 1973; Clancy, Jacobsen \& Silva, 1976; Bloom, Lahey, Hood, Lifter \& Fiess, 1980). Other studies (e.g. Hood \& Bloom, I979; Bloom \& Capatides, 1987) focused on children's expressions of causal relations independently of their linguistic form and showed that children in their third year can indeed express these relations before they have the specific linguistic means to do so. However, all the subjects in Hood \& Bloom's study were already far advanced in combinatorial speech, for at the beginning of the study their least advanced subject (Peter at 2; I) had an MLU of 2.0. Dunn (1988) reported that very young children may provide justifications and excuses in situations of a conflict with their mother or with their siblings. She reported that some justifications were produced by the age of $\mathrm{I} ; 6$ but no examples were provided nor was any information given concerning the level of language development of these children. Most of the examples were produced by children in their third year who were already well advanced in combinatorial speech.

In this paper, the appearance and development of references to the past and of explanatory acts are analysed at an early period of language development - from the time children start producing a few one-word utterances to when the use of several multi-word utterances becomes frequent - and are analysed in the same children in order to get a better understanding of single- and successive single-word speakers' ability to make displaced, informative-type references, despite their limited means of expression. Furthermore, the pattern of appearance of two such functional changes - early references to the past and early justifications - may provide an interesting source of evidence concerning the child's gradual apprehension of other persons as being in need of information. In other words, the child's increasing use of language for talking about objects, persons and events not in the immediate situation or about non-perceptible, past or future aspects of a present situation might constitute indirect evidence of children's changing attitudes towards their interlocutors: children may start to apprehend their interlocutor as not 
having their mind on what they themselves are thinking or paying attention to, and language may thus gradually become a means of sharing states of mind.

\section{METHOD}

\section{Subjects}

The data reported here concern four normally developing children, growing up in a French-speaking environment. The families were middle-class and all lived in Geneva, Switzerland; they were contacted either through friends or in the Genevan public parks. Three of the children are girls (Camille, Chantal and Amandine) and one is a boy (Gael) and they were all followed from the time they started to produce a few (no more than 10 ) conventional words until they produced several two-word utterances. Camille was followed between the ages of $1 ; 3.2$ and I; 10. I 2; Chantal, between the ages of $1 ; 4.12$ and $1 ; 7.19$; Amandine, between the ages of $1 ; 5.14$ and $1 ; 11.22$; and Gael, between the ages of $1 ; 4 \cdot 3$ and 2;3.4. Both Camille and Chantal have one older sibling, while Amandine and Gael are single children.

\section{Data collection and transcription}

The families were visited in their homes approximately every two weeks by the same two observers. Audio and video recordings lasting about an hour were made of the children during spontaneous interaction with one family member (usually the mother), in a variety of naturally occurring situations. Sometimes, particularly during the second half hour of the session, one of the observers also took part in the interaction. All sessions included free play and book-reading situations, and in most sessions the children also engaged in spontaneous pretend play. Often, eating situations were also part of the recordings. The analyses reported here concern a total of 50 hours of interaction.

Transcriptions of the children's speech and of other persons interacting with them were made primarily from the videotapes, complemented, when necessary, by the audiorecordings. Transcription of children's speech remained close to actual pronunciation (transcribed mainly in IPA); adult speech was transcribed in conventional French orthography. Transcripts include detailed information about non-verbal activities that contribute to understanding what was said. All transcriptions were first made by one of the observers and checked at least once by a second person. Many tapes were then viewed again; disagreements were generally resolved during this phase through joint repeated listening/viewing. 


\section{The analyses}

References to the past. First we identified children's utterances that referred or might refer to past events. Adults' utterances discussing past events which were not followed or preceded by a child's utterance on that topic were not analysed in this study. Interpretation of the children's utterances was based on contextual as well as on discursive information preceding and following the utterance, and took into account the various utterances that the children produced to talk about a particular past event.

(i) Initiation of the theme. Children's references to the past were first classified according to whether it was the adult or the child who INITIATED THE THEME of the past reference and the classification thus distinguished child-initiated (see example I below) from adult-initiated themes (see example 2 below):

(1) Camille at $1 ; 9.3$

(Camille has fallen from her rocking horse; she goes to her mother who helps her to sit on her knee)

Child bé

Mother t'es tombée? 'you fell down?'

Child põpõ obbé (pointing behind in the direction of the rocking horse) Mother ah oui t'es tombée de Ponpon 'oh yes you fell from Ponpon' (the name of the horse)

(2) Chantal at 1;5.10

(Chantal wants to continue playing at 'hide and seek'; her mother tries to interest her in something else)

Mother qu'est ce qu'on est allé chercher hier avec Mélanie? 'what did we go to look for yesterday with Mélanie?'

Child ekaye

Mother des cailloux et puis quoi? 'pebbles and what else?'

Child efei

Mother des feuilles. Elles étaient belles les feuilles hier hein? 'leaves. They were nice the leaves yesterday weren't they?'

Child we! 'yeah!'

(ii) Contributions to the theme. There is, however, more to referring to past events than initiating talking about them. An event usually comprises several elements or aspects at different moments and involves different objects or persons (see also Eisenberg, $1985: 180$ ). When the adult initiated the theme, 
the children would react in different ways: they ignored the proposal either by not replying at all or by talking about something else; they replied with an imitative uptake of a lexical element contained in the adult's turn; or they contributed to the proposed theme by evoking an aspect of the event that was not explicitly referred to by the adult. We thus distinguished in the children's production three main categories of references to aspects of past events independently of who initiated the theme:

(a) Uptakes from the adult (UPTAKEs in tables and figures): the child's references occur only after $s /$ he heard them in the adult's utterances:

(3) Chantal at I; 5 . I0

(Chantal's mother is talking about activities in nursery school the day before)

Mother il y avait des marionnettes à la crèche hein?

'there were puppets at the nursery, yes?'

Child demayonet

'puppets'

(b) New contributions by the child where it is unclear whether the past or the present is referred to (UNCLEAR CONTRIBUTIONS). The aspects mentioned by the child were not referred to previously but it is the adult's interpretation that situates them in the past: the child may have uttered them to refer to present objects or events:

(4) Camille at $I ; 5.23$

Child dadé (holding a doll-clown in her hand)
marché/marcher
'walked/to walk'
Mother le clown a marché avant?
'the clown walked earlier on?'
Child dade (making the doll-clown stand up on the floor)
Mother ou on le fait marcher comme avant?
'or we make him walk as before?'

(c) New contributions by the child where the reference to the past is clear (CLEAR CONTRIBUTIONS): the aspects referred to are contributed to the conversation by the child and cannot be interpreted as referring to present objects or events. They can be elicited by specific adult's questions, follow the adult's directive to tell (raconte qu-est-ce qu'il a fait le docteur 'tell (us) what the doctor did') or contribute a new aspect in an unsolicited way, as in the following example:

(5) Chantal at $1 ; 6.21$

(With reference to a picture in the book, Chantal's mother talks about Father Christmas and recounts how Chantal's sister recited a poem. Spontaneously, Chantal adds) 
Child avo (clapping her hands)

'bravo'

Mother bravo oui, tout le monde a dit bravo

'bravo yes, everybody said bravo'

(iii) Temporal distance. As was done in other studies (e.g. Sachs, 1983; Miller \& Sperry, I 988 ; Ely \& McCabe, I 993), we distinguished references to the 'immediate' past, i.e. to events having occurred during the same observational session, from references to an 'earlier' past, i.e. to events having occurred before the observational session. The following are two examples of child-initiated talk about the past containing new and clear contributions of the child: example 6 concerns the immediate past and example 7 the earlier past:

(6) Camille at $1 ; 5.23$

Child bé bé (looking and pointing at the base of a mechanical frog she holds in her hand)

'tomber/tombé'

'fall/fallen'

Adult c'est tombé

'it fell'

Child bé (looking at the adult and pointing at the same time to the spot on the floor where the frog had fallen earlier on)

'tomber/tombé'

'fall/fallen'

Adult c'est tombé par terre? (the child looks at the adult and smiles) 'it fell on the floor?'

(7) Gael at I ; I I I

(Gael is putting plastic chips into a toy-truck. He stops and looks at his mother)

Child bubel

'poubelle'

'rubbish'

Mother quoi poubelle?

'what about the rubbish'

Child pati

'gone'

Mother ah oui parce qu'on a vu un camion poubelle ce matin.

Il est venue et il est reparti.

'ah yes because we saw a rubbish van this morning.

It came and drove off again.'

Some of the references to the past do not fall into these two categories. The 
temporal distance of the event from the present is indeterminate as they are mini-stories about book characters:

(8) Chantal at $1 ; 6.2 \mathrm{I}$

(Chantal, sitting on the floor, plays with little dolls and toy prams)

Mother où est la poupée?

'where is the doll?'

Child epum (looking at her mother)

Mother elle est tombée?

'she fell?'

Child (shakes head negatively and adds)

adam

'(the) lady'

Mother la dame?

'the lady?'

Child pum

Mother la dame elle est tombée oui la dame du livre

'the lady fell yes the lady in the book'

Child ay!

Mother aïe ça fait mal

'ouch it hurts'

Explanations/justifications. Utterances classified as such had to fulfil at least three criteria. Firstly, the two parts of an explanation - the explanandum, that which needs to be explained and the explanans, that which explains-should be expressed in some way. The explanans should be expressed verbally while the explanandum may be marked in a nonverbal way (by actions and/or gestures). Secondly, the verbalization should be addressed and there should not be reasons to believe that it could refer to ongoing actions or events. Thirdly, the event should be considered as an explanandum-something the child might consider to be a problem for himself and/or for his interlocutor. The following example fulfils these criteria. At I ;8.12 Camille, after having tried without success to open a sliding match box, handed it to her mother and said, while looking at her, /Oppa/ roughly for peux pas 'can't'. In this example, the explanans - the child's incapacity to open the matchbox - is verbalized while the explanandum - the request itself - is marked by the child's action of handing the matchbox to the mother and by looking at her; the utterance identified as the explanans is produced while the child handed the object over and not during the child's unsuccessful trials to open the matchbox; the act of requesting is likely to be considered by the child as an explanandum since her mother often encouraged the child to do things herself. 


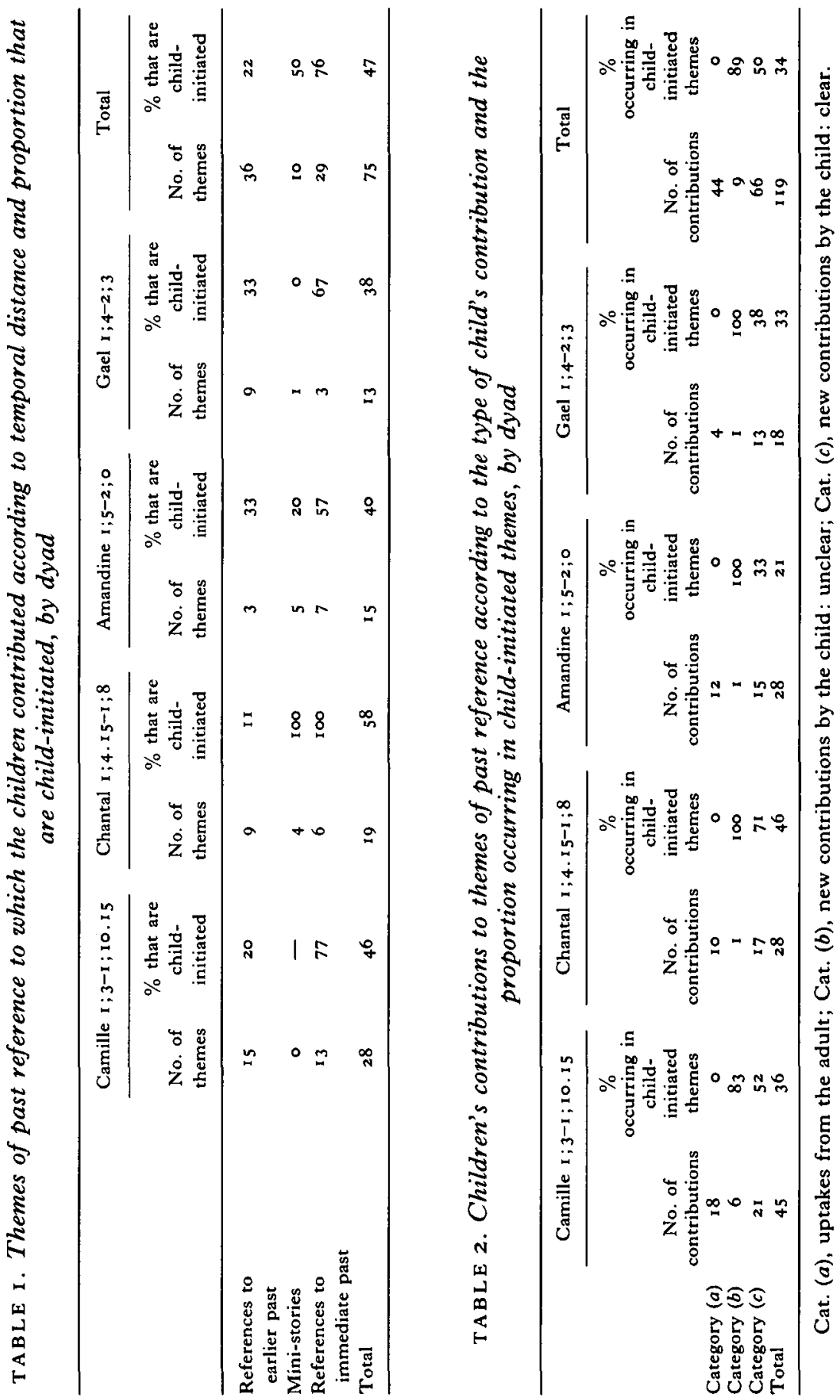




\section{RESULTS}

\section{References to the past}

References to past events were found for all four children well before the age of two, expressed by single-word, successive single-word, and early twoword utterances.

\section{Cumulative results}

Table I provides the number of themes evoked by each dyad according to whether they concern the immediate past, the earlier past or whether they are mini-stories, and the proportion of themes initiated by the children. All four dyads contributed to the total of 75 themes, of which $48 \%$ concerned the earlier past, $39 \%$ the immediate past and $13 \%$ were mini-stories. Adults initiated the majority of the themes concerning the earlier past (an average, over dyads, of $78 \%$ ); however, contrary to Lucariello \& Nelson's ( 1987 ) study which found no child-initiated talk about the past up to $2 ; 5$, in our study 8 of the 36 conversations referring to earlier past $(22 \cdot 2 \%)$ were initiated by the children. Moreover, the children initiated most of the themes concerning the immediate past (an average, over dyads, of $76 \%$ ).

The adults had various ways of initiating talk about the past. Sometimes they asked a general elicitation question (e.g. raconte qu'est-ce qu'on a vu 'tell us what we saw') or a more specific one (e.g. avec qui t'as été sur le carrousel? 'who were you with on the merry-go-round?'); sometimes they started with a question to which they themselves provided the answer (e.g. où est-ce que t'as bu du Coca Cola? au McDonald? 'where did you drink Coke? at McDonald's?'), or they began talking about a past event by simply appealing to the child's memory (e.g. looking at the child who is manipulating his sunglasses, the mother says tu te rappelles qu'on les a mis en vacances quand il $y$ avait du soleil? 'do you remember we put them on in the holidays when the sun was shining?').

The children initiated talk about the past by verbalising an element of the event that might be an object or a person (e.g. /pã/pain, 'bread' given to the swans; /bubsl/poubelle 'rubbish' which was there early in the morning; /e'tin/ 'Christine' who sewed the button on the jacket); by talking about what they had just done (e.g. /etwaye/ nettoyer/nettoye' 'to clean/cleaned' after having cleaned the clown's feet; /eassé/ repassé 'ironed' after having finished ironing with a toy iron; /põpõ obbe/Ponpon tomber/tombe' 'Ponpon to fall/fallen', meaning that the child fell off her toy horse named Ponpon) or by talking about what happened to objects/persons (e.g. /pum/talking about a lady in a book who lies on the ground - the book was not visible at the time-; /omi/dormi, 'slept' talking about a doll she had taken out of bed; /ga aglas/ 'look mirror' meaning that the doll had looked at herself in the mirror). 
Concerning the number of elements or aspects of past events referred to, the four children, taken together, made a total of i i 9 contributions (see Table 2 which presents the cumulative number of child-mentioned aspects according to whether they were contributions of category $(a)(b)$ or $(c)$, and whether they occurred in child-initiated or in adult-initiated themes, per child). The mean number of references per session, from the time they started to appear in the children's production, indicates that Amandine, Camille and Chantal produced more of such references than Gael (the mean number of aspects verbalized per session was, respectively, $4.7,5,5.6$ for the girls and $\mathrm{I} \cdot 6$ for the boy). Summed up over the whole period studied, new and clear contributions of the child (category $(c)$ ) are the most numerous $(55.5 \%)$ : Gael and Amandine produced them more frequently in adultinitiated themes, Chantal produced them more frequently in child-initiated themes and Camille produced them about equally in both. Uptakes (category (a) ) constitute $37 \%$ of all children's contributions and all occurred in adultinitiated themes. New but unclear contributions (category $(b)$ ) constitute $7.5 \%$ of the total and occurred mostly in child-initiated themes $(89 \%$ of them).

Among the new and clear contributions made by the children, $71 \%$ were produced without having been specifically elicited by a wh-question or by a directive to tell (see Table 3 ). The proportion of such unsolicited production

T A B LE 3. New and clear contributions by the child according to temporal distance and elicitation by the adult, per child

\begin{tabular}{|c|c|c|c|c|}
\hline & Earlier past & Mini-stories & Immediate past & Total \\
\hline \multicolumn{5}{|l|}{ Camille } \\
\hline Number & 13 & 0 & 8 & $2 I$ \\
\hline$\%$ NEA * & 46 & - & 88 & 62 \\
\hline \multicolumn{5}{|l|}{ Chantal } \\
\hline Number & 5 & 6 & 6 & 17 \\
\hline$\%$ NEA & 60 & 100 & 100 & 88 \\
\hline \multicolumn{5}{|l|}{ Amandine } \\
\hline Number & 5 & 4 & 6 & 15 \\
\hline$\%$ NEA & 40 & 75 & 83 & 67 \\
\hline \multicolumn{5}{|l|}{ Gael } \\
\hline Number & 7 & 5 & I & 13 \\
\hline$\%$ NEA & 71 & 60 & 100 & 69 \\
\hline \multicolumn{5}{|l|}{ Overall } \\
\hline Number & 30 & 15 & 21 & 66 \\
\hline$\%$ NEA & 53 & 80 & 90 & 71 \\
\hline
\end{tabular}

* $\%$ NEA, $\%$ non elicited by adult specific $w h$-questions or directives. 
is higher for references to immediate past $(90.5 \%)$ and mini-stories $(80 \%)$ than for references to distant past $(53 \%)$.

A minimum of $15 \%$ (Gael) of themes and a maximum of $46 \%$ (Camille) contained more than one contribution by the child, mainly in adult-initiated themes (see Table 4). The mean number of children's contributions was, for each of the four dyads, higher in adult-initiated than in child-initiated themes. This is possibly because the adults may have solicited more from the child when they themselves initiated a theme than when the child did so; furthermore, it was the adults who initiated most of the themes concerning the distant past and it may be supposed that there is more to say about earlier than about the immediate past, the former comprising a large span of experience, while talk about the latter usually highlights but a brief experience.

TABLE 4. Number of past reference themes with $2(+)$ child's contributions and mean number of children's contributions per theme, per child

\begin{tabular}{lllll}
\hline & Camille & Chantal & Amandine & Gael \\
\hline $\begin{array}{l}\text { No. (and \%) of themes with 2(+) } \\
\text { contributions }\end{array}$ & $13(46)$ & $6(31)$ & $3(20)$ & $2(15)$ \\
$\begin{array}{l}\% \text { occurring in child-initiated themes } \\
\text { Mean number of contributions per }\end{array}$ & 23 & 33 & 0 & 50 \\
theme & 1.61 & 1.47 & 1.87 & 1.38 \\
All & 1.23 & 1.18 & 1.00 & 1.20 \\
In child-initiated themes & 1.93 & 1.88 & 2.44 & 1.50 \\
In adult-initiated themes & &
\end{tabular}

Whether child- or adult-initiated, the themes were often elicited by an element present in the situation, for example, by a still perceptible result of a previous action or by a picture in a book. As Table 5 shows, this is the case for at least $90 \%$ of the themes evoked by dyads with Camille, Amandine and Gael, the percentage being instead lower for the dyad with Chantal $(57 \%)$. Most of the themes (between 73 and $100 \%$ ) were first mentions and most of them were referred to only once in our documents. We evaluated the repetitive or routine nature of the events to which the children made new and clear contributions and found that between 56 and $60 \%$ of the themes evoked might concern recurring events. This percentage is higher than the overall measure of $24 \%$ of routine activities occurring in the past talk of the ten 2-2; 5 subjects of Lucariello \& Nelson's study ( $1987: 225$ ), but lower than the measures provided by Eisenberg ( $198_{5}: 18_{5}$ ) for the age period comparable to that of our subjects (between 82 and $93 \%$ for one child between $1 ; 9$ and 2 ; 0 and between 75 and $83 \%$ for the other child between $2 ; 3$ and $2 ; 9$ ). Most 
TA В LE 5. Themes with children's new contributions (cat. (b) and/or cat. (c)) according to presence of cues in the situation, frequency of recorded talk, estimation of repetitive/routine activities and self-involvement

\begin{tabular}{lccccc}
\hline & Camille & Chantal & Amandine & Gael & Total \\
\hline Cues in situation & 20 & 8 & 9 & 9 & 46 \\
$\begin{array}{l}\text { Cues in discourse } \\
\% \text { of new contributions cued in } \\
\text { situation }\end{array}$ & 2 & 2 & 1 & 0 & 5 \\
$\begin{array}{l}\text { First mention } \\
\text { No. }\end{array}$ & 57 & 90 & 100 & 84 \\
$\quad \%$ & 16 & 10 & 10 & 7 & 43 \\
$\quad \begin{array}{l}\text { Repetitive/routine } \\
\text { No. }\end{array}$ & 73 & 71 & 100 & 78 & 78 \\
$\quad \%$ & 13 & 8 & 6 & 5 & 32 \\
Reference implies self & 59 & 57 & 60 & 56 & 58 \\
$\quad$ No. & 19 & 7 & 6 & 8 & 40 \\
$\%$ & 86 & 50 & 60 & 89 & 73 \\
\hline
\end{tabular}

of the themes to which the children contributed concerned events in which the child was personally involved.

\section{Developmental results}

The age at which children produced their first references to past events varied: 1 ; 4 for Camille, I; 5 for Chantal, $I ; 7$ for Amandine, and $1 ; 8$ for Gael. The first references the children made to the past occurred in conversational contexts either as partial imitations of aspects evoked by the adult (category $(a)$ ) or, if they were new contributions produced by the child, they were ambiguous as to whether they made reference to the past or to the present (category (b)). Clear references to aspects of past events contributed by the child (category $(c)$ ) appeared, for the four children, one month after these first occurrences and then became increasingly frequent. Fig. I presents the occurrence of these different types of reference for each child.

Concerning category $(c)$ - new and clear contributions of the child - for three of the children (Camille, Chantal and Amandine), references to the immediate past and mini-stories (when they occurred) appeared at about I ; 5 , I; 6 and I; 8 and preceded references to the earlier past; the latter occurred one month later for Camille and Chantal and three months later for Amandine. By contrast, the first new and clear contributions made by Gael were to the earlier past and appeared at about I;9 (see Fig. 2).

References to the past were thus produced by the children during our period of observation, but not at its very beginning. This, of course, does not mean that as early one-word speakers children had no memories of past 

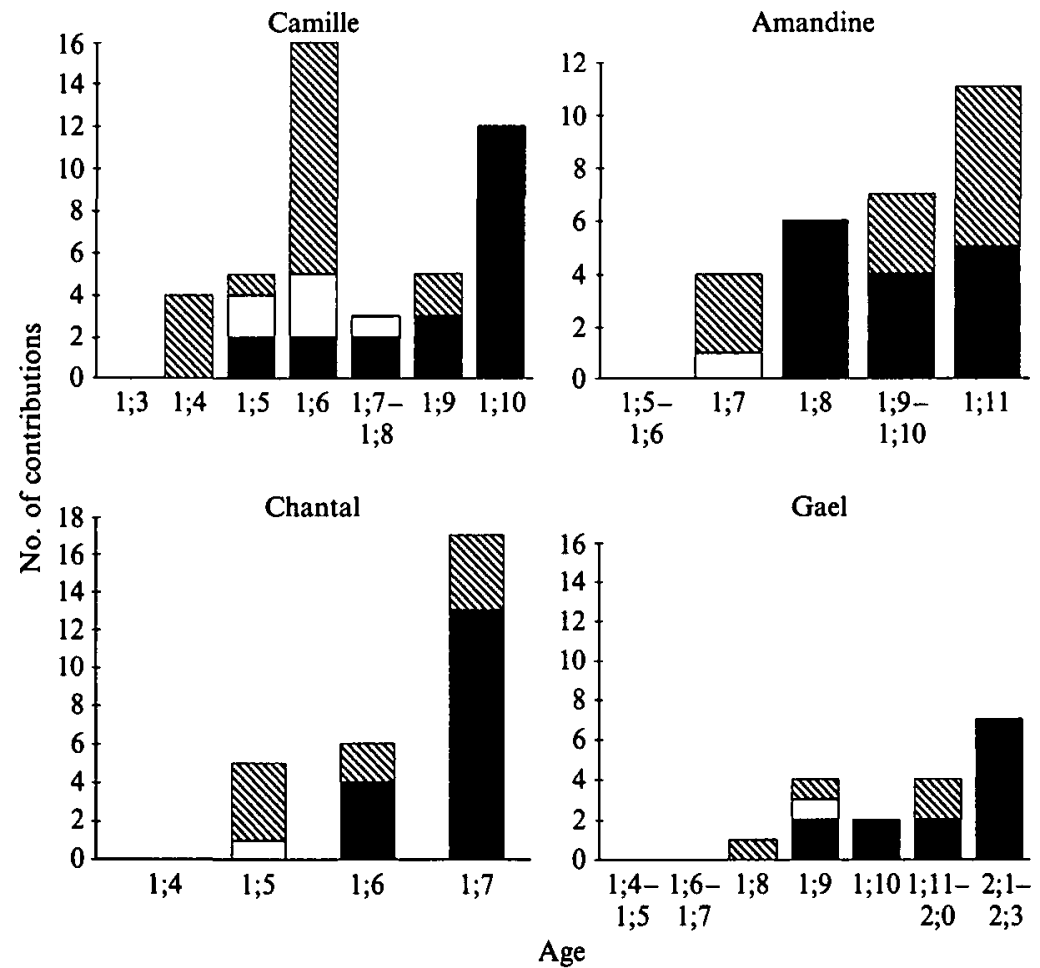

Fig. I. Children's contributions to references to the past, by child and by age. $\mathbb{Q}$, Cat. (a) uptakes; $\square$, cat. (b) new contributions: unclear; $\boldsymbol{D}$, cat. (c) new contributions: clear.

events; but that memories are not a sufficient condition for talking about past events (Eisenberg, 1985). To us this change suggests that children, as they become more competent, both cognitively and socially, find a new functional use for their utterances. This new use suggests that children in this period start to understand what might be pertinent to tell their listener (Sachs, 1983 : $2 \mathrm{I}$ ) and that the newly mastered capacity to conventionally relate signifiers to signifieds can be put to powerful use in the interests of communication.

This capacity is not immediate across the board, but starts in close relation to the adult's production, first as imitative uptake, and then as a sequel to the adult's initial evocation of a past event, though the aspect of the event mentioned by the child constitutes an original contribution which is far from being always specifically elicited by the adult. Child-initiated references to the past appear at first for events that have just happened with only a few aspects of the experience mentioned. As soon as they appear, new and clear contributions by the child concern not only the evocation of events that are routinized, frequent or often talked about but also specific happenings in the past that are mentioned in our records for the first time. 


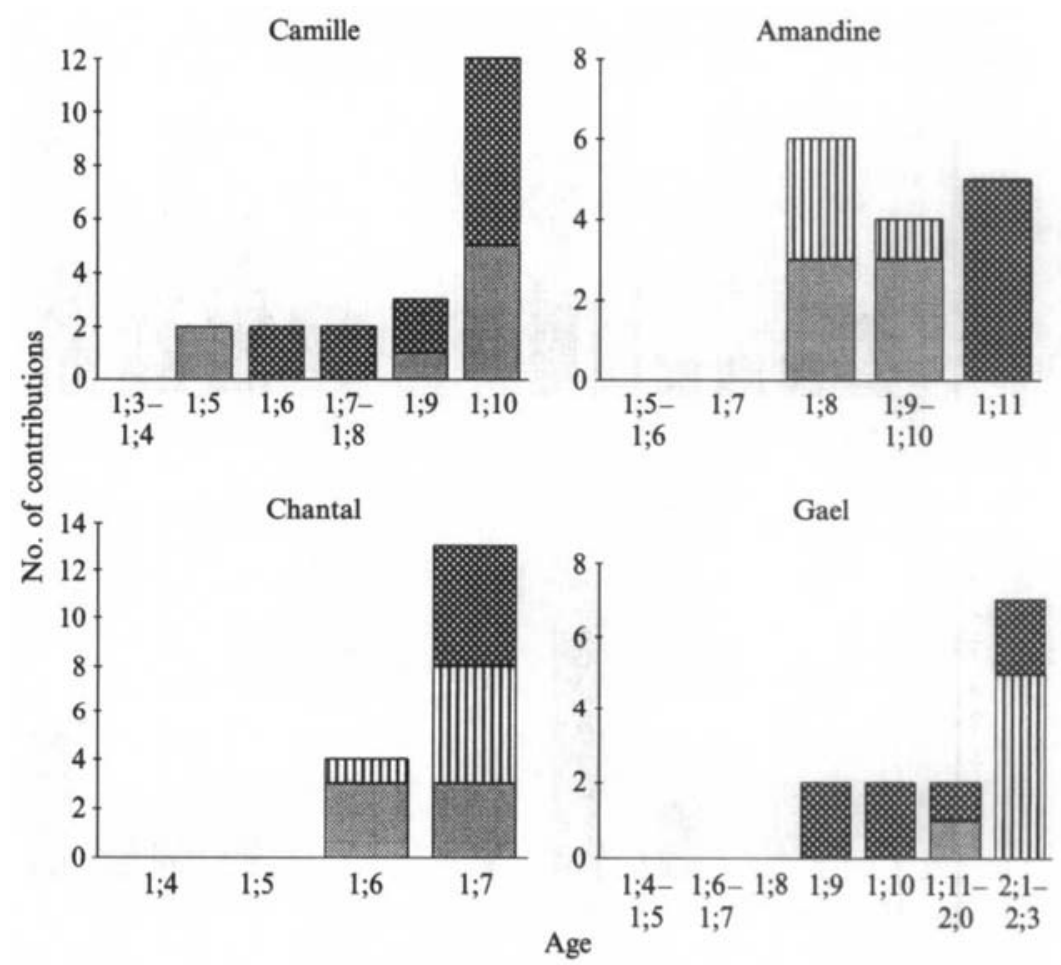

Fig. 2. References to immediate past, to earlier past and mini stories in children's new and clear contributions, by child and by age. 8 , References to earlier past; 四, mini-stories; 圈, references to immediate past.

\section{Explanations and justifications}

The first examples of justifications, like those of references to the past, appeared when the children were still essentially single-word speakers and were observed in different situations. Sometimes the children produced justifications for their own behaviour. For example, at $1 ; 6.22$, Camille gave a bottle which still contained some juice to her mother saying /py/, plus, 'no more', not to wrongly state that there was no more juice in the bottle, but to give the reason why she handed the still half-filled bottle to her mother, a verbalization well understood by the latter (M.: t'en veux plus? 'you don't want any more?'). Justifications and explanations were also produced to account for real or imaginary behaviours occurring in pretend play episodes. At $\mathbf{1} ; 8.20$, for example, Amandine said /fwa/, froid, 'cold' while she tried to put a toy shoe on to a doll's foot, explaining the reason for her doing it. At I;8. I 5 Camille, looking at her mother, says /oppa/, roughly meaning veut pas, 'doesn't want', after having said, in her previous turn, /plœ/, pleure, 'cries', talking about a small baby doll she had just placed in a plastic box 
serving as a bath-tub: the utterance /oppa/ explains the reason for the baby doll's 'crying' (pretended by the child) by invoking the baby's internal state of dislike relative to the bathing situation.

The developmental status of the appearance of explanations or justifications can be particularly well demonstrated by analysing two specific communicative situations: that of request and that of refusal/denial. Requests and refusals occurred at all observational sessions from the beginning of our study and were expressed by all the children in certain ways. Such naturally recurring situations are precious for the analysis of observational data: they provide an in-built control since they show that opportunities to exhibit the focused behaviour existed all along. Thus if explanations and justifications occur in these situations, it will be possible to evaluate their occurrence in relation to that of other behaviours.

\section{Verbalizations in requests and in refusals/denials}

Our subjects, like many other children described in the literature, used their early utterances to verbalize a variety of communicative functions including requests. During a certain period, they verbalized one or another of the different aspects of a request, e.g. the desired object, the action or the result

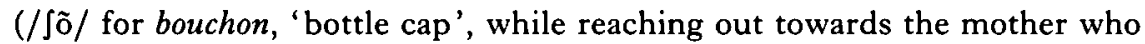
held a bottle cap; / tun/ for tourne, 'turn', while handing a spinning top to the mother for making it turn; /ecru/ for trou, 'hole', while handing a punching machine and a piece of paper to the mother); or they verbalized the person who was to perform the action (e.g. /mamã/, 'mummy', while handing a spinning top to the mother) or the action that should be carried out so that the child can obtain the desired object (for example, /ovi/ for ouvrir 'open', while handing a box containing baby dolls to the mother).

At some point in this development a new behaviour appeared: while performing the gestures that allowed their communicative act to be identified as a request, the children did not verbalize components of the request but provided the reason for the request, justifying for their adult interlocutor the request itself. For example, Camille handed a box she could not open to her mother saying /e'ppa/, peux pas, 'can't'; Gael handed a video-cassette holder to his mother saying /edy/, roughly c'est dur, 'it's hard', and Chantal handed her mother a doll, from which she had unsuccessfully tried to remove the pants, saying /e'ppa/, roughly peux pas, 'can't'. The interactional histories of these children show that their mothers encouraged them to attain their goals by themselves. In these examples, by justifying their request, the children provided their mother with a good reason to help them without further delay. It is interesting to note that claims of incapacity ('I can't do it') are also frequently provided by children in their third and fourth year as justifications of requests (Hood \& Bloom, 1979; Barbieri et al. 1990) and for 
TABLE 6. Requests, refusals/denials and their justifications by child and by age

\begin{tabular}{|c|c|c|c|c|}
\hline \multirow[b]{2}{*}{ Child/age } & \multicolumn{2}{|c|}{ Number } & \multicolumn{2}{|c|}{$\%$ with justification } \\
\hline & Requests & $\begin{array}{c}\text { Refusals/ } \\
\text { denials }\end{array}$ & Requests & $\begin{array}{c}\text { Refusals/ } \\
\text { denials }\end{array}$ \\
\hline \multicolumn{5}{|l|}{ Camille } \\
\hline $1 ; 3.2-1 ; 7.4$ & 82 & 52 & o & $\circ$ \\
\hline $1 ; 7.18-1 ; 10.12$ & 45 & 22 & $35 \cdot 5$ & $68 \cdot 2$ \\
\hline \multicolumn{5}{|l|}{ Chantal } \\
\hline $1 ; 4.12-1 ; 5.17$ & 29 & 18 & 0 & $\circ$ \\
\hline $1 ; 6.0-1 ; 7.19$ & 49 & 56 & $14 \cdot 3$ & $16 \cdot 1$ \\
\hline \multicolumn{5}{|l|}{ Amandine } \\
\hline $1 ; 5 \cdot 14^{-1} ; 7.2$ & 24 & 5 & 0 & 0 \\
\hline I;8.6-1; 1 I.22 & 27 & 62 & 37 & $24 \cdot 2$ \\
\hline \multicolumn{5}{|l|}{ Gael } \\
\hline $1 ; 4.3^{-1} ; 8.6$ & 65 & 8 & 0 & $\circ$ \\
\hline $1 ; 9.0-2 ; 3.4$ & 100 & 48 & 15 & $25^{\circ} 0$ \\
\hline
\end{tabular}

declining their parents' demand for assistance in some task (Dunn, 1988: $3 \mathrm{I}$ ). One of our subjects, Camille, observed at a later session (not analysed here) when she was $2 ; 2$ produced a much more explicit utterance, $j$ 'arrive pas maman, tiens ' $I$ can't do it mommy, here it is', handing to her mother a doll that she wanted to undress, to similarly justify her request.

The appearance of these justifications is clearly not due to the children's acquisition of new lexical items like 'can't' or 'hard'. Indeed, they already knew these words, and had used them previously while experiencing difficulties in reaching their goal; it is only later that they used them as justifications in a request act.

Another type of justification was encountered in contexts of refusal and denial. At first, when the children verbalized their refusal to carry out an action, or to follow a suggestion made by the adult, they simply said non. Later, verbalizations of refusals were sometimes followed by a justification, often indicating what should be done instead. For example, Chantal at $\mathrm{I} ; 6$ refused her mother's help and said non; then, immediately afterwards, while looking at her mother before resuming her activity, added/tusel/, toute seule, 'all by myself'; Gael, at I; 10.17, by saying non, refused the adult's suggestion to build a train and immediately added, looking at the adult, bébé 'baby'; it was not till later that he went to the toybag to look for baby dolls. Though these utterances are the expression of what the child wants to do, they can be considered to provide an explanation of refusal since they are addressed specifically to the adult interlocutor before the child goes about realizing the intended goal. The verbalization seems to be produced in order 
FUNCTIONAL CHANGES IN EARLY CHILD LANGUAGE

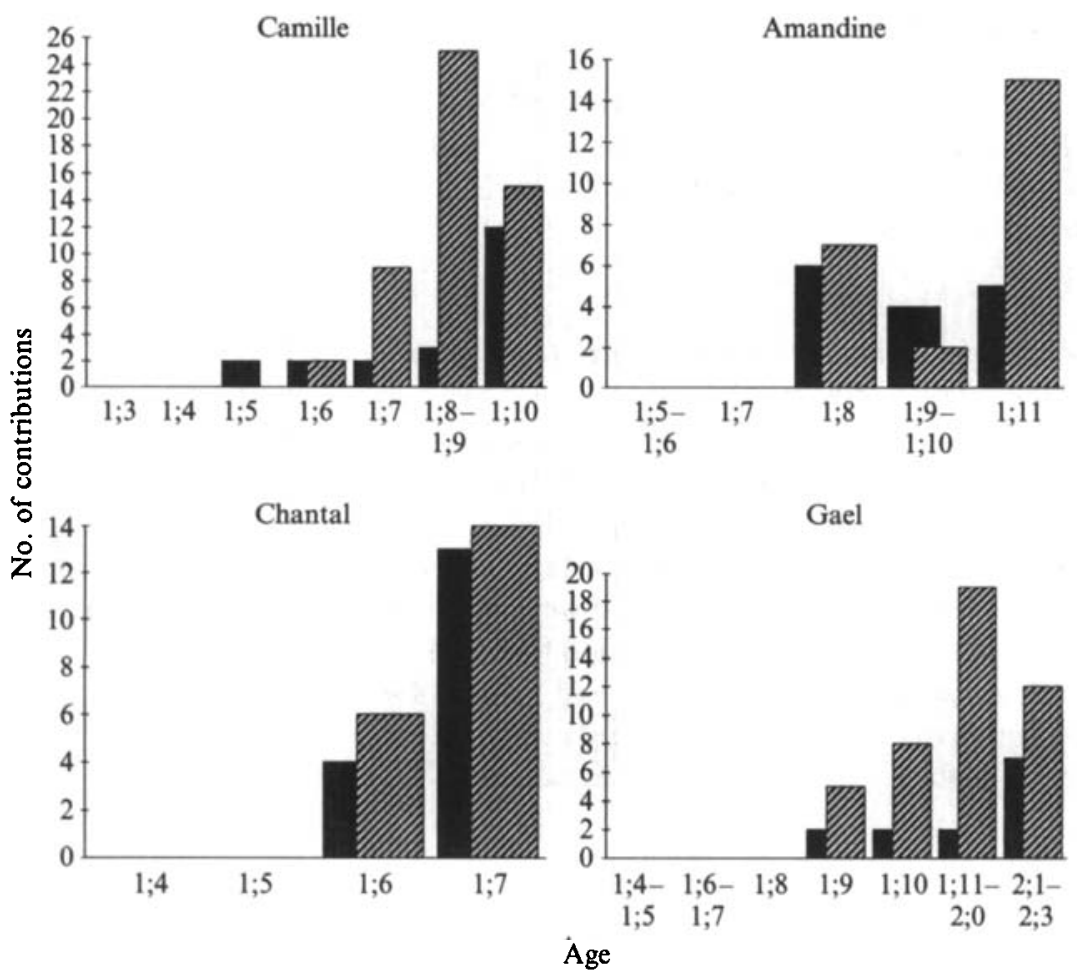

Fig. 3. Temporal relation between the occurrence of references to the past and of explanatory acts, by child and by age. Number of new and clear references to the past contributed by the child; $叉$, number of explanations/justifications.

to foil the adult's proposal, making the child's refusal more understandable and thus more likely to be accepted.

Children may also contradict an adult's statement, the denial being sometimes followed by a justification that may be regarded as a primitive form of argumentation. For example, Amandine, at I ; I I 22, contradicted the adult who, in a game, asserted that a red chip was green: Amandine said non and looking at the adult justified her denial by adding rouge 'red'.

As can be seen in Table 6, quantitative analysis of all communicative acts of requests and refusals/denials occurring during the whole study shows that the four children verbalized requests and refusals (and thus occasions for explanations or justifications) right from the start of our observations. But it is only at a certain point in development that explanations are provided in these contexts, though the frequency of the phenomena and the age at which they were first observed for each child differed (at $1 ; 6$ for the earliest and $I ; 9$ for the latest). 
Thus, in the case of Camille, for the 82 requests verbalized between $1 ; 3.2$ and $\mathrm{I} ; 7.4$, no clear justification was produced. A justification was provided in $35.5 \%$ of the 45 requests verbalized between $1 ; 7.18$ and I; IO. I 2 . As for refusals, 52 were observed between $1 ; 3.2$ and $I ; 7.4$, none being followed by an explanation. An explanation followed in $68.2 \%$ of the 22 refusals/denials observed between $1 ; 7$. I 8 and I; I0. I 2 .

\section{Temporal relation between references to the past and explanations/justifications}

According to the hypothesis that references to the past and explanatory utterances are both manifestations of a new, informative use of language that brings out the signifier-to-signified direction of semanticity, we expected a close temporal relation in the appearance of these behaviours. As Fig. 3 shows, clear references to the past introduced by the child and explanatory utterances appear at the same session for three of the four children: at $1 ; 6$ for Chantal, at $1 ; 8$ for Amandine and at $1 ; 9$ for Gael. For Camille, clear references to the past were observed at $1 ; 7$, one observational session, i.e. two weeks, before the appearance of explanations.

\section{DISCUSSION}

Our data show that references to the past and explanations/justifications appear at a very early period of language acquisition, earlier than is generally assumed in the literature, and that at first they are expressed by simple linguistic means the children had at their disposal before starting to produce them. Concerning references to the past, our results show that though children initiate more talk about the immediate than about the earlier past, they also initiate talk about the latter and make new contributions to themes about the earlier past initiated by the adult. Moreover, children's new contributions not only refer to repetitive, routine activities but also to specific, unique events.

The early appearance of explanations is surprising; it is interesting to note, though, that they occur quite often in requests which constitute communicative acts that infants are reported to perform quite early and well before the appearance of identifiable words (e.g. Harding, I 983).

The co-appearance of references to the past and explanations/justifications supports our hypothesis that both are manifestations of the children's apprehension of a socio-cognitive, communicatively functional feature of human speech, i.e. its informative potentialities. What processes can be invoked to account for this development?

On the one hand, it may be supposed that the ability to use language in a 
way that is detached from the perceptible situation at the moment of speaking naturally extends the child's earlier elaboration of the relation between signifier and signified: signifiers acquire a mental reality of their own that can evoke the signified in the same way as the signified may elicit the signifier (cf. the reversal of the relation 'object/meaning' and 'action/meaning' referred to by Vygotsky (1933/1967) in his analysis of symbolic play). The development of this capacity is related to the more general cognitive evolution that takes place in the second half of the first year and the beginning of the second year of life when infants start to be less dependent on what is immediately perceived and on the actions they are performing.

On the other hand, there appears to be a socio-cognitive development by which the interlocutor begins to be viewed by the child as an alter ego - a person whose psychological states may be different from the child's own. This development relates to a topic, much discussed in recent literature, that came to be known as the child's 'theory of mind'. One of the central questions in this domain is the following: when does the child begin to assume that persons have minds and that their behaviour is regulated by what they want, feel, think or believe, though these desires, feelings, thoughts and beliefs may not necessarily find clear observable expression? (Butterworth, Harris, Leslie, \& Wellman, I991). Research findings suggest that in the second half of their second year children can attribute certain internal states to other people and differentiate them on the basis of surface cues, as attested by their manifestations of empathy towards a distressed adult or by the positive or negative value they attribute to a new object or situation on the basis of the adult's emotional reaction (cf. Bretherton, McNew \& BeeghlySmith, 1981 ; Kagan, I987; Dunn, 1988). Children in their second year show several other behaviours whose meaning can hardly be understood without supposing that they take other persons' psychological states into consideration: teasing, for example, which implies an understanding of what might annoy or amuse another person (a behaviour whose early manifestations are claimed to be found already towards the end of the first year (Reddy, I 99 I )), and pretend play in so far as it involves verbalization of inner states attributed to pretend characters (Dunn, I99I). During this same period e.g. between $1 ; 6$ and 1 ; 10 in Lamb's (199I) study-children start to use lexical items such as sad, happy, hurt for internal states and items such as good, bad, nice for social values.

We think that our findings provide further data that can contribute to a better understanding of development in this domain.

We observed the appearance of two kinds of displaced, informative language uses at around the same time in the late single-word period: talking about past experiences and providing simple explanations. Though references to the past also occur when children are alone and 'talking for themselves' (cf. Piaget, I945/195 I, observation no. 104), they of ten occur in 
conversation with adults, as observed in our study. In this setting, references to the past may provide new information to an interlocutor who was not present or was not paying attention at the time of the recalled experience, or they may serve as reminders of a shared past experience which is in the child's own mind. Such use of language implies attributing to one's interlocutor a lack of knowledge or a shared memory-knowledge of a particular past event.

In a different but functionally similar way, explanations and justifications - besides being social moves that improve children's chances to have their way - verbalize states that are not observable to the interlocutor because they are internal to the child or are attributed by the child to the characters of his/her pretend play. Moreover, in so far as explanations are mentally constructed links between explanans and explanandum, they are inherently not directly accessible to another person. The appearance of explanations thus constitutes another instance in which language is used to signal to one's interlocutor aspects of an event/situation which s/he is unlikely to know about. Our data on explanations and justifications occurring in situations of request and refusal/denial provide a particularly clear case in favour of this interpretation: these interactional situations occur from our earliest observational sessions; moreover, when children begin to produce explanations/ justifications they use words they had already in their vocabulary but used earlier with a different function. Thus the absence of such functional uses of language at the earlier period cannot be ascribed to a lack of opportunity for producing justifications nor to a lack of lexical items for expressing them.

The appearance of explanations/justifications at a certain time in our longitudinal records, and their co-appearance with first references to the past, thus strongly suggest a change in the way children view their interlocutor, to whom they now seem to attribute mental states different from their own and that need to be taken into account in interpersonal relations: mental states that can be changed by attempts to persuade, by the expression of one's own (different) intentions and ideas, or by attempts to make the other share one's own mental focus of attention.

Some authors consider behaviours whose meaning appears to depend on making reference to internal states of an alter ego, as the beginnings of a theory of mind, whereas others argue that no theory of mind can be considered to begin before the age of 4 , and that younger children's intersubjectivity should be interpreted as a 'fairly sophisticated mentalistic theory of behavior' (Perner \& Wilde-Astington, I992: 142). We agree with Dunn (1988:66) that this attitude towards others should be viewed as a kind of 'practical' understanding without the implication that children reflect on others' feelings and mental states. Differentiation between self and others on this practical level is in line with the achievements of sensorimotor intelligence (at around $1 ; 6$ ) giving rise to what Piaget calls a 'Copernican 
revolution' that eventually places the child in a universe of external objects and persons:

As soon as the schema of substantial and permanent objects is acquired, and especially at the level of intuitive intelligence, persons become other 'egos' at the same time as the ego itself is being constituted and becoming a person (Piaget 1945/1962: 207).

It is interesting to note that in the period under study the child is observed only to offer the interlocutor a piece of information or to lead him/her into a situation the child can share. At most this is evidence that the child considers the other as not knowing or not paying attention to what the child knows or pays attention to, but we have no indications that the other is seen by children as knowing something they themselves do not know.

Since children's 'mindreading' abilities cannot be inferred from a single kind of behaviour but only from 'a broad range of aspects' (Dunn, I 99 I : 52), future research should include other types of informative language uses within this perspective.

Another element related to these developmental changes can be sought in the utterances that adults address to children. It has often been reported that, in their conversations with children who are beginning to speak, caretakers mostly talk about the here and now - a practice that is likely to foster the acquisition of the meaning of words and sentences. In our data, the adults similarly produced few straightforward references to the past but we noted that, while talking about present entities and ongoing actions, they use subtle means that link the present situation to the past or the future, to absent persons and objects or to aspects of the present situation that are not easily or not at all accessible to simple observation (Veneziano \& Georgakopoulos, 1993). For example, they may link a present to an earlier action/object by using words like 'again', 'another' and the prefix 're-' as in refaire 're-do' or 'do again'; they may link present objects to absent ones by making comparisons (e.g. c'est comme la barbe de papa 'that's like Daddy's beard'), link present states to preceding physical or intentional causes (e.g. fa a tout coulé à côté/t'as bu trop vite 'it spilled all over/you drank too fast') or verbalize non perceptible properties of present objects or beings (e.g. fa c'est la roue qui tourne 'that's the wheel that turns', pointing at a plastic reel lying on the floor), often talking about internal states, (e.g. le chien là il a faim 'the dog there is hungry'). In this way, adults find a solution that reconciles two apparently divergent needs: on the one hand, the need to remain close to the immediate situation so as to provide a clear frame for the child to construct signifier-signified relations and, on the other, the need to use language in its habitual 'informative' way, that is, to talk about aspects of a situation that, without language, would be difficult to communicate. These adult uses of language in which displacement is provided with a built-in contextual 
support provide another important source for the functional changes observed in children's talk.

\section{REFERENCES}

Barbieri, M. S., Colavita, F. \& Scheuer, N. (1990). The beginning of the explaining capacity. In G. Conti-Ramsden \& C. Snow (eds), Children's language. Vol. 7. Hillsdale, NJ: Erlbaum.

Bloom, L. (1970). Language development : form and function in emerging grammars. Cambridge, MA : MIT Press.

Bloom, L. \& Capatides, J. B. (1987). Source of meaning in the acquisition of complex syntax: the sample case of causality. Journal of Experimental Child Psychology 43, i i 2-28.

Bloom, L., Lahey, M., Hood, L., Lifter, K. \& Fiess, K. (1980). Complex sentences: acquisition of syntactic connectives and the semantic relations they encode. Yournal of Child Language 7, 235-6 I.

Bloomfield, L. (1935). Language. London: Allen \& Unwin.

Bretherton, I., McNew, S. \& Beeghly-Smith, M. (198I). Early person knowledge as expressed in gestural and verbal communication: when do infants acquire a 'theory of mind'? In M. E. Lamb \& L. R. Sherrod (eds), Infant social cognition. Hillsdale, NJ: Erlbaum.

Brown, R. \& Bellugi, U. (1964). Three processes in the child's acquisition of syntax. Harvard Educational Review 34, I33-5 I.

Butterworth, G., Harris, P., Leslie, A. \& Wellman, H. (I 99I). Editorial Preface to the special issue 'Perspectives on the child's theory of mind'. British Yournal of Developmental Psychology 9, 1-4.

Clancy, P., Jacobsen, T. \& Silva, M. (1976). The acquisition of conjunctions: a crosslinguistic study. Stanford Papers and Reports on Child Language Development 12, 7 I-80.

Cohen, M. (1952/1969). Sur l'étude du langage enfantin. Enfance 3/4, 203-72.

Dunn, J. (1988). The beginnings of social understanding. Cambridge, MA : Harvard University Press.

- (1991). Understanding others: evidence from naturalistic studies of children. In A. Whiten (ed.), Natural theories of mind. Oxford: Blackwell.

Eisenberg, A. R. (1985). Learning to describe past experiences in conversation. Discourse Processes 8, $177^{-204}$.

Ely, R. \& McCabe, A. (1993). Remembered voices. Fournal of Child Language 20, 671-96.

Greenfield, P. M. \& Smith, M. (1976). The structure of communication in early language development. New York: Academic Press.

Harding, C. G. (1983). Setting the stage for language acquisition: communication development in the first year. In R. M. Golinkoff (ed.), The transition from prelinguistic to linguistic communication : issues and implications. Hillsdale, $\mathrm{NJ}$ : Erlbaum.

Hockett, C. F. (1958). A course in modern linguistics. New York: Macmillan.

Hood, L. \& Bloom, L. (1979). What, when and how about why: a longitudinal study of early expressions of causality. Monograph of the Society for Research in Child Development 44 (6), Serial no. 181 .

Kagan, J. (1987). Introduction. In J. Kagan \& S. Lamb (eds), The emergence of morality in young children. Chicago: University of Chicago Press.

Lamb, S. (1991). Internal state words: their relation to moral development and to maternal communications about moral development in the second year of life. First Language Ir, $391-406$.

Lewis, M. M. (1936). Infant speech : a study of the beginnings of language. New York: Harcourt Brace.

Limber, J. (1973). The genesis of complex sentences. In T. E. Moore (ed.), Cognitive development and the acquisition of language. London: Academic Press.

Lucariello, J. \& Nelson, K. (1987). Remember and planning talk between mothers and children. Discourse Processes 10, 21 9-35.

Lyons, J. (1977). Semantics. Vol. I. Cambridge: C.U.P. 


\section{FUNCTIONAL CHANGES IN EARLY CHILD LANGUAGE}

Miller, P. J. \& Sperry, L. L. (1988). Early talk about the past: the origins of conversational stories of personal experience. Fournal of Child Language 15, 293-315.

Nelson, K. (1986). Event knowledge. Hillsdale, NJ: Erlbaum.

Perner, J. \& Wilde-Astington, J. (r 992). The child's understanding of mental representation. In H. Beilin \& P. B. Pufall (eds), Piaget's theory. Hillsdale, NJ: Erlbaum.

Peterson, C. (1990). The who, when and where of early narratives. Yournal of Child Language 17, 433-55.

Peterson, C. \& McCabe, A. $\left(\mathrm{g}_{983}\right)$. Developmental psycholinguistics: three ways of looking at a child's narrative. New York: Plenum Press.

Piaget, J. (1923). Le langage et la pensée chez l'enfant. Neuchâtel: Delachaux et Niestlé. (English translation (1959). The language and thought of the child. London: Routledge \& Kegan Paul.)

— (1945). La formation du symbole chez l'enfant. Neuchâtel: Delachaux et Niestlé. (English translation (1962). Play, dreams and imitation in childhood. New York: Norton \& Co.)

Reddy, V. (1991). Playing with others' expectations, teasing and mucking about in the first year. A. Whiten (ed.), Natural theories of mind. Oxford: Blackwell.

Sachs, J. (1983). Talking about the there and then: the emergence of displaced reference in parent-child discourse. In K. E. Nelson (ed.), Children's language. Vol. 4. Hillsdale, NJ: Erlbaum.

Scollon, R. ( ( 979 ). A real early stage : an unzippered condensation of a dissertation on child language. In E. Ochs \& B. B. Schieffelin (eds), Developmental pragmatics. New York: Academic Press.

Snow, C. E. (1978). The conversational context of language acquisition. In R. N. Campbell $\& \mathrm{P}$. T. Smith (eds), Recent advances in the psychology of language : language development and mother-child interaction. New York: Plenum Press.

Veneziano, E. \& Georgakopoulos, J. (1993). Is early mother-child discourse really tied to the hic et munc? Paper presented at the Sixth International Congress for the Study of Child Language. Trieste, Italy.

Vygotsky, L. S. (1933/1967). Play and its role in the mental development of the child. Soviet Psychology 5, 6-1 8. 